Yet teamwork, technology and business sense are essential for the survival of the British economy.

But what if you cannot even bring the horse to the water, let alone persuade him to drink properly ? The symposium depressed itself with speculation about the reasons why young people may now be reluctant to go in for science and technology. Again there seemed to be general agreement that the young are infected with a "new fatalism" and have no vision of a golden future to which science and technology may contribute and no inkling of the enthusiasm which professional scientists have for their work. It was all good gloomy stuff. One of these days something may be done about it.

\section{Instant Teachers}

How long does it take to turn a student of the humanities into a science teacher? Three years is the answer given by Nottingham Regional College of Technology. In its new Department of Education, Nottingham is basing its acceptance of candidates for its three year Certificate of Education course in science teaching on general ability and interest in science teaching as well as academic qualifications in science. Thus if a candidate can demonstrate his ability in other subjects and his interest in science teaching, the college will accept him even if he does not know one end of a thermometer from the other.

Because of the shortage in applications from science candidates to teacher training colleges and universities, the department has decided not to compete for pure scientists but to offer Applied Science and a second opportunity to those who opted for the humanities instead of science at school. As the courses are designed for the Nuffield programme of science teaching, where a feel for the subject is much more important than facts, it is hoped that general ability will make up for any lack of specific knowledge.

The courses will tend towards either Biological Sciences or Physical Sciences and an Engineering course is under discussion. The students of the physical seiences will spend four terms working on American courses, which start from first principles for beginners but allow scientists to be rapidly directed into more profitable work. The teaching scheme is based on individual study rather than lecture programmes, and tutors will make much use of written material, acting as directors of study and tailoring the work to each student's needs. Students will also be able to take short courses from a range which will include Computer Science, Chemical Technology, Building Science, Food Science, Materials Science and Mechanical Engineering. These short courses should enable the students to base their teaching on practical applications when they go into the schools.

Nottingham Regional College of Technology is one of five technical colleges-the others are John Dalton College, Manchester, Sunderland Technical College, Barking Regional College of Technology and North Western. Polytechnic-which are now running courses for the Certificate of Education. Previously these three year courses could only be taken at Colleges of Education. The Principal Lecturer, in charge of the science courses at Nottingham, is Dr Michael Bassey, who will be remembered for his trenchant criticisms of school science syllabuses at the British Association. meeting in 1961 .

\section{More Cancer Research}

A NEW research block consisting of laboratories for Tumour Immunology and Radiobiology was opened at Sutton, Surrey, on September 27. The unit is part of the Chester Beatty Research Institute, and the $£ 150,000$ it cost has come from the Napier Trust, the British Empire Cancer Campaign, the Medical Research Council and other donations. Block $\mathrm{X}$, as it is called, has been operational since June, only 17 months after the idea for such a unit was suggested. Because the unit is alongside the Sutton branch of the Royal Marsden Hospital, it is hoped that any positive results that are obtained will be speedily applied.

Work has been going on for some time on various forms of immunotherapy, and in particular the treatment of primary sarcomata by injection of either immunized lymphocytes or of immunized cancer cells, that is, cells taken from the tumour, after removal by surgery, and rendered "sterile" by irradiation. Some of the impetus for the new research unit has come from research described earlier this year by Alexander, Delorme, Hamilton and Hall (Nature, 213, 569). Evidence has been found in animals of host resistance to tumours, and it is hoped that by boosting this reaction by the injection of immune lymphocytes it will be possible to provide some control. This form of treatment would be particularly important after surgery.

Under some conditions this treatment has proved successful in experimental animals, but it is emphasized by the staff of the new unit that experience of this treatment is too limited for any definite conclusions to be drawn. The mechanism of the cytotoxic action of lymphocytes is also being studied.

American workers S. H. Nadler and G. E. Moore have also carried out transplant experiments in which tumours from two patients were transplanted to each other and after 10-14 days lymphocytes from each patient were transfused back to the other to fight the original growth. In several cases remission of the cancer for considerable lengths of time has occurred. This method of treatment is also being considered for investigation at the new unit.

\section{Refining Steel}

Electro-slaG Refining Technology, the British Iron and Steel Research Association's first development unit which was formed to exploit the electro-slag refining process, has fully justified its existence in its 15 months of operation on a commercial basis. It has recorded widespread use of its hire and contract facilities and has been responsible for a number of technical developments. Five plant manufacturers have entered into agreements with ESRT, and have installed or are installing fourteen plants with ingot producing capacities ranging from 8 to 36 in. The unit has also supplied. 250 ingots to some twenty-five customers, covering a range of thirty-five alloys. The ingots have enabled customers to evaluate the electroslag refining process. 224 ingots have been made on a miniature plant in thirty-eight individual contract evaluation programmes for fourteen clients. As a result of these studies, techniques have been developed for production melting of many alloys both in Britain and overseas.

Electro-slag refining is as secondary refining process 
for producing quality controlled steels and alloys in fairly high tonnages. It is economically competitive with other processes at present used, as the capital outlay is fairly low and the running cost is the same as if not cheaper than the other processes.

\section{Shocks in Store}

The bid by the General Electric Company for Associated Electrical Industries seems to have taken AEI by surprise. AEI is taking a week to think about the bid, worth $£ 120$ million in stock and cash, before committing itself to a view. GEC has offered five GEC shares and $80 \mathrm{~s}$. cash for every eight AEI shares, which effectively puts a value of $52 s$. $1 d$. on the AEI shares against a market price before the bid of $43 \mathrm{~s} .6 \mathrm{~d}$. By October 3, AEI shares stood at 56s. 4.5d., as high as they have been this year, indicating a feeling among investors that AEI will offer at least some opposition to the takeover. The terms, AEI is likely to claim, are based on a poor performance by AEI last year, and a forecast of profits of about $£ 9.2$ million this year. It is likely to add that better times are on the way, but shareholders have been told this many times before. GEC profits are far more buoyant, running at about twice those of AEI, although GEC is a much smaller group.

Both companies employ large research departments. AEI has a large central research laboratory at Rugby, which carries out basic research for the whole company as well as contract research work for government and other companies. AEI Power Group has a laboratory at Trafford Park in Manchester which includes among its interests scientific instruments, traction and magnetohydrodynamic power generation. The Telecommunications Group runs two laboratories, one at Blackheath and one at Harlow, and the Cables Group has a laboratory at Gravesend concerned with insulating materials, and one at Woolwich studying high voltage phenomena. The joint AEI-Thorn semiconductor company also runs a research department.

GEC's main laboratory is the Hirst Research Centre in North Wembley, named after Sir Hugo Hirst, the founder of the company. This has divisions serving all branches of the business-lamps and lighting, telecommunications, electronics, valves and semiconductors. It also includes three divisions doing more fundamental work, in engineering, metallurgy and electronics materials, and a division which supplies chemical and technical services. In addition, GEC Electronics runs two applied electronics laboratories, at Stanmore and Portsmouth, and there is another telecommunications laboratory at Coventry. The Osram lamp company has two laboratories, and other companies associated with GEC also run their own development laboratories.

If the takeover goes through, some rationalization of this mass of laboratories seems inevitable. This is particularly likely in electronics, where the new group would hold 40 per cent of the market. GEC has a joint semiconductor company with Mullard, while AEI shares its electronics interests with Thorn; if the deal is successful, GEC hopes to merge these interests and, save money on research. It is not yet clear how the deal would affect AEI's nuclear power interests-it owns 10 per cent of the shares of the Nuclear Power Group, Ltd. GEC's association with nuclear power ended some years ago, and was not a happy one. GEC was involved in the building of an unsuccessful power station in Japan, and still has problems to solve at the Hunterston $A$ station which it built. AEI's nuclear power interests have certainly been more profitable than this, but whether this would encourage GEC to go back into nuclear power as part of the Nuclear Power Group, or pull out altogether, is still not clear.

\section{Laboratory of All Trades}

SEWAGE is unattractive but inescapable. At the Water Pollution Research Laboratory, the staff continues to study it with every evidence of enthusiasm, and this year is spending $£ 360,000$ both on the treatment of sewage and on its effects when allowed to escape. A scheme in collaboration with the Hydraulies Research Station and a firm of consulting engineers is intended to find the ideal position for sewage outflow in the Thames Estuary. In parallel, the laboratory is studying the effect of pollution on fish, together with the related problems of the variation and measurement of oxygen concentration in streams and rivers.

The laboratory has been hard at work on the two chief methods of biological treatment- the activated sludge process and biological filtration. One interesting development is the use of plastic filters in biological filtration, and a system has been devised for controlling automatically the intensity of aeration so as to maintain oxygen at an optimum concentration. A new treatment of sewage, by chemical oxidation at high temperatures and pressures, is undergoing preliminary investigation, and as a means of reaching high pressures it has been suggested that the sewage be poured into very deep holes in the ground. The laboratory is optimistic about the change from hard to soft detergents; this, it says, has had the effect of markedly reducing the amount of foam in rivers. The manufacturers and the laboratory are hoping to find even softer detergents, and are conducting an experiment at a small sewage works serving a village community specially supplied with experimental detergent by the manufacturers.

Pollutants are also studied at the Warren Spring Laboratory, but in this case air is the dispersion medium. The laboratory provided background information for the Clean Air Act and is at present completing a five-year national survey of smoke and sulphur dioxide. Smoke concentration in the air has been falling, and although total emission of sulphur dioxide has risen slightly, the overall concentration of the gas has fallen.

Recovery of metals from scrap, studies of process control and separation of dry minerals by air fluidization form an important part of the work of the mineral science and technology section and the chemical engineering section. Both work in consultation with industry. The chemical engineering section has considerable interest in catalysts. A pilot plant producing acetone by dehydrogenation of isopropanol has been linked to a computer for process control studies, but this system has limited application. Control by simple logic systems of batch processes such as distillation of binary mixtures is being studied and is likely to be more useful. The laboratory employs a staff of 440 , and is expanding slightly year by year, with annual expenditure standing currently at $£ 1$ million. 